\title{
Epicatechin-3-Gallate Signaling and Protection against Cardiac Ischemia/Reperfusion Injurys
}

\author{
Yiyao Qi, ${ }^{1}$ Changjun Yang, ${ }^{1}$ Zhen Jiang, Yin Wang, Feng Zhu, Tao Li, Xiaochun Wan, \\ Yunhui Xu, Zijian Xie, Daxiang $\mathrm{Li}$, and Sandrine V. Pierre
}

State Key Laboratory of Tea Plant Biology and Utilization, Anhui Agricultural University, Anhui, China (Y.Q., C.Y., F.Z., T.L., X.W., D.L.); International Joint Laboratory on Tea Chemistry and Health Effects of Ministry of Education, Anhui Agricultural University, Hefei, China (Y.Q., F.Z., T.L., X.W., D.L.); Department of Neuroscience, Mcknight Brain Institute, University of Florida, Gainesville, Florida (C.Y.); Marshall Institute for Interdisciplinary Research, Marshall University, Huntington, West Virginia (Z.J., Y.X., Z.X., S.V.P.); Gladstone Institute of Cardiovascular Disease, The J. David Gladstone Institutes, San Francisco, California (Z.J.); and Institute of Health Food, Zhejiang Academy of Medical Science, Hangzhou, China (Y.W.)

Received May 22, 2019; accepted September 9, 2019

\begin{abstract}
At concentrations found in humans after ingestion of one to two cups of green tea, epicatechin-3-gallate (ECG) modulates $\mathrm{Na} / \mathrm{K}-\mathrm{ATP}$ ase conformation and activity. Akin to ouabain, an archetypal $\mathrm{Na} / \mathrm{K}-\mathrm{ATP}$ ase ligand of the cardiotonic steroid (CTS) family, ECG also activates protein kinase C epsilon type $(\mathrm{PKC} \varepsilon$ ) translocation and increases the force of contraction of the rat heart. This study evaluated whether, like ouabain, ECG also modulates $\mathrm{Na} / \mathrm{K}-\mathrm{ATP}$ ase/Src receptor function and triggers pre- and postconditioning against ischemia/reperfusion (I/R) injury. In vitro, ECG activated the purified $\mathrm{Na} / \mathrm{K}-\mathrm{ATPase} /$ Src complex. In Langendorff-perfused rat hearts, submicromolar concentrations of ECG administered either before or after ischemia reduced infarct size by more than $40 \%$, decreased lactate dehydrogenase release, and improved the recovery of cardiac function. ECG protection was blocked by $\mathrm{PKC} \varepsilon$ inhibition and attenuated by mitochondrial $\mathrm{K}_{\mathrm{ATP}}$ channel inhibition. In a unique mammalian cell system with depleted $\mathrm{Na} / \mathrm{K}$-ATPase $\alpha 1$ expression, ECG-induced $\mathrm{PKC} \varepsilon$ activation persisted but protection against I/R was blunted. Taken together, these results reveal a Na/K-ATPase- and $\mathrm{PKC} \varepsilon$-dependent mechanism of protection by ECG that is also distinct from the mechanism of action of ouabain. These ECG properties

likely contribute to the positive impact of green tea consumption on cardiovaascular health and warrant further investigation into the role of cardiac $\mathrm{Na} / \mathrm{K}-\mathrm{ATP}$ ase signaling in the cardioprotective effect of green tea consumption.

\section{SIGNIFICANCE STATEMENT}

Consumption of green tea, the richest dietary source of ECG, is associated with a reduced risk of cardiac mortality. Antioxidant effects of ECG and other tea polyphenols are well known, but reported for concentrations well above dietary levels. Therefore, the mechanism underlying the cardioprotective effect of green tea remains incompletely understood. This study provides experimental evidence that ECG concentrations commonly detected in humans after consumption of a cup of tea trigger the $\mathrm{Na} / \mathrm{K}-\mathrm{ATPase} / \mathrm{Src}$ receptor in a cell-free system, activate a CTS-like signaling pathway, and provide $\mathrm{PKC} \varepsilon$-dependent protection against ischemia/reperfusion injury in rat hearts. Mechanistic studies in mammalian cells with targeted $\mathrm{Na}$ / $\mathrm{K}$-ATPase depletion revealed that although $\mathrm{Na} / \mathrm{K}-\mathrm{ATPase}$ does not mediate ECG-induced $\mathrm{PKC} \varepsilon$ activation, it is required for ECG-induced protection against ischemia/reperfusion injury.
\end{abstract}

\section{Introduction}

Green tea polyphenols such as epicatechin-3-gallate (ECG) and epigallocatechin-3-gallate have received much attention for their natural antioxidant properties and potential use as

This work was supported by the Anhui Provincial Natural Science Foundation [Grant 1508085MC59]; the Anhui Major Demonstration Project for the Leading Talent Team on Tea Chemistry and Health, Chang-Jiang Scholars and the Innovative Research Team in University [Grant IRT1101]; the Earmarked Fund for China Agriculture Research System (CARS-19); and Marshall Institute for Interdisciplinary Research Funds.

${ }^{1}$ Y.Q. and C.Y. contributed equally to the work.

https://doi.org/10.1124/jpet.119.260117.

S This article has supplemental material available at jpet.aspetjournals.org. nontoxic treatments for a number of health conditions (Higdon and Frei, 2003; Kuriyama et al., 2006; Baghdadi et al., 2018). Like other plant-derived antioxidant polyphenols, tea polyphenols have a dual nature and can also act as pro-oxidants, generate reactive oxygen species, and cause oxidative stress (Babich et al., 2011). Green tea polyphenols have also been attributed to biologic activities that are apparently not directly related to those redox properties (Feng et al., 2010; Kim et al., 2014; Yang et al., 2016). For example, they have been shown to afford protection during myocardial ischemia/reperfusion (I/R) through modulation of the expression of transcription factors (e.g., nuclear factor- ${ }_{-} \mathrm{B}$ and activator protein-1), reduction of signal transducer and activator of transcription-1 (STAT-1)

ABBREVIATIONS: Akt, protein kinase B; CTS, cardiotonic steroid; ECG, epicatechin-3-gallate; ERK, extracellular signal-regulated kinase; 5-HD, 5hydroxydecanoate; I/R, ischemia/reperfusion; KH, Krebs-Henseleit; LDH, lactate dehydrogenase; LVDP, left ventricular developed pressure; PKC $\varepsilon$, protein kinase $\mathrm{C}$ epsilon type; PostC, postconditioning; PreC, preconditioning; TIP, translocation inhibitor peptide. 
activation and Fas receptor expression, and increase in nitric oxide production (Darra et al., 2007).

We have reported that catechins from green tea stimulate protein kinase $\mathrm{C}$ epsilon type $(\mathrm{PKC} \varepsilon)$ in the heart, and subsequently increase myocardial contraction. Of the identified compounds, ECG was the most effective (Li et al., 2008). The observed ECG-induced activation of cardiac PKC $\varepsilon$ occurred within minutes of exposure to concentrations that are commonly detected in humans after consumption of a cup of tea, and is therefore a plausible contributor to the observed health benefits associated with green tea consumption (Fung et al., 2013). PKC $\varepsilon$ activation is a hallmark of cardioprotection against I/R injury triggered by preconditioning (PreC) and/or postconditioning (PostC) (Inagaki et al., 2006; Chen et al., 2016), including PreC/PostC induced by low concentrations of Na/K-ATPase-specific ligand cardiotonic steroids (CTSs) (Pierre et al., 2007; D'Urso et al., 2008; Duan et al., 2015, 2018; Marck and Pierre, 2018). Ochiai et al. (2009) have shown that within the same physiologic range of concentrations ECG does modulate $\mathrm{Na} / \mathrm{K}$-ATPase conformation and enzyme activity, which prompted us to explore whether this property could confer the galloyl-type catechin CTS-like ability to trigger the $\mathrm{Na} / \mathrm{K}$-ATPase/Src/PKC $\varepsilon$-based cardioprotective signaling.

Accordingly, this study examines whether dietary concentrations of ECG activate the $\mathrm{Na} / \mathrm{K}$-ATPase/Src receptor in vitro and trigger $\mathrm{PKC} \varepsilon$-dependent protection against $\mathrm{I} / \mathrm{R}$ via PreC and PostC mechanisms in the Langendorff-perfused rat heart preparation.

\section{Materials and Methods}

Chemicals. Green tea epicatechin-3-gallate (purity $\geq 98 \%$ ), mitochondrial $\mathrm{K}_{\mathrm{ATP}}$ channel blocker 5-hydroxydecanoate (5-HD), and lactate dehydrogenase (LDH) activity assay kit TOX-7 were purchased from Sigma Chemical Co. (St. Louis, MO). The phosphate assay kit (A070-2) used for pre-I/R cardiac Na/K-ATPase measurements was purchased from Nanjing Jiancheng Bioengineering Institute (Nanjing, China), and PKC $\varepsilon$ translocation inhibitor peptide (TIP) was obtained from Calbiochem (La Jolla, CA). All other reagents were of analytical grade.

Purified Pig Kidney Na/K-ATPase Preparation, Cell-Free $\mathrm{Na} / \mathrm{K}$-ATPase Enzyme Activity, and Na/K-ATPase/Src Receptor Assay. Na/K-ATPase was purified from pig kidney outer medulla using the Jørgensen and Collins (1986) method as we have previously described, and preparations with specific activities between 1200 and $1400 \mu \mathrm{mol} \mathrm{Pi} / \mathrm{mg}$ per hour were used in this work. Under our experimental conditions, either $100 \mu \mathrm{M}$ vanadate or $10 \mu \mathrm{M}$ ouabain caused complete inhibition of the ATPase activity of the purified pig kidney Na/K-ATPase (Tian et al., 2006). For activity measurements, the purified $\mathrm{Na} / \mathrm{K}$-ATPase was incubated in a reaction mixture containing $100 \mathrm{mM} \mathrm{NaCl}, 20 \mathrm{mM} \mathrm{KCl}, 3 \mathrm{mM} \mathrm{MgCl}_{2}, 20 \mathrm{mM}$ Tris ( $\mathrm{pH}$ 7.4), $1 \mathrm{mM}$ EGTA, and $5 \mathrm{mM} \mathrm{NaN}_{3}$. After 10 minutes of preincubation at $37^{\circ} \mathrm{C}, 2 \mathrm{mM} \mathrm{ATP} / \mathrm{Mg}^{2+}$ was added to start the reaction for 10 minutes. The reaction was stopped by adding $8 \%$ ice-cold trichloroacetic acid. The phosphate generated during the ATP hydrolysis was measured using the BIOMOL GREEN reagent (Enzo Life Science). Na/K-ATPase activity was calculated as the difference between ATPase activities measured in the presence or absence of $2 \mathrm{mM}$ ouabain. To determine the ECG dose-response curve, the $\mathrm{Na} / \mathrm{K}$-ATPase preparation was preincubated with the indicated concentrations of ECG for 10 minutes before ATP was added to start the reaction. The Na/K-ATPase/Src receptor function was assessed as previously described (Tian et al., 2006) with minor modifications. Briefly, purified recombinant Src (4.5 U) was incubated with $5 \mu \mathrm{g}$ of purified pig kidney $\mathrm{Na} / \mathrm{K}$-ATPase in detergent-free $\mathrm{PBS}$ for 30 minutes

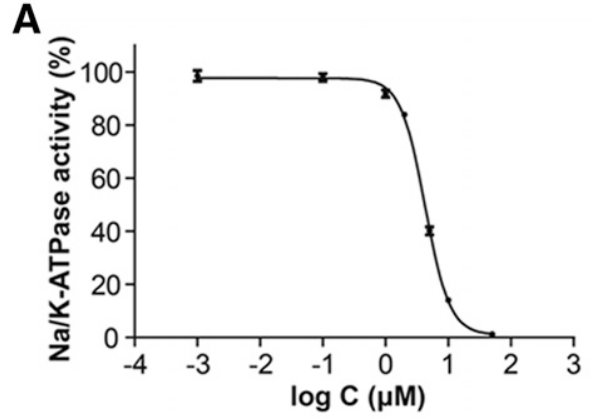

B
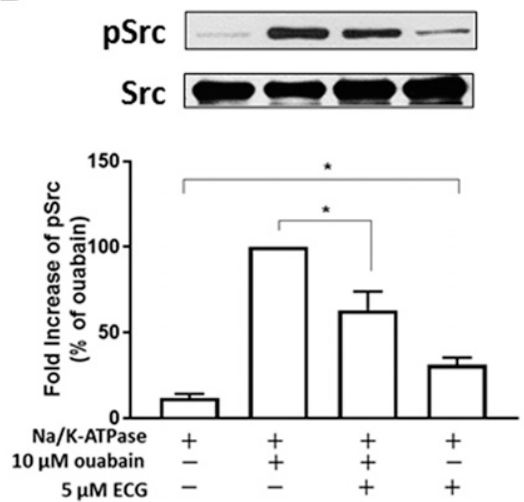

Fig. 1. Effects of ECG on Na/K-ATPase activity and the receptor function of the Na/K-ATPase/Src complex. (A) The indicated concentrations of ECG were incubated with an equal amount of purified pig kidney Na/K-ATPase. The ouabain-sensitive ATPase activity was then measured and plotted. Values are mean \pm S.E.M. $(n=4)$. Values from all doses were fit with a four-parameter logistic curve $\left(R^{2}=0.9958\right.$, Hill slope $\left.=-2.227\right)$. The calculated $\mathrm{IC}_{50}$ value was $4.267 \mu \mathrm{M}$. (B) Purified Src (4.5 U) was incubated with $5 \mu \mathrm{g}$ of purified pig kidney Na/K-ATPase in the presence of vanadate and ATP $/ \mathrm{Mg}^{2+}$ and the indicated treatment of 15 minutes. Src pY418 and total Src were assessed by western blotting with specific antibodies. The ratio of pY418 Src/total Src was calculated and expressed as the percentage of the ouabain group \pm S.E.M. $(n=3)$. ${ }^{*} P<0.05$ vs. indicated group.

at $37^{\circ} \mathrm{C}$. After adding $2 \mathrm{mM} \mathrm{ATP} / \mathrm{Mg}^{2+}$ and $100 \mu \mathrm{M}$ vanadate, the reaction was allowed for 15 minutes at $37^{\circ} \mathrm{C}$ and stopped by addition of SDS sample buffer. Vanadate $100 \mu \mathrm{M}$ was added to all assays to completely inhibit the ATPase activity of Na/K-ATPase in this reaction, and therefore prevent changes in ATP availability that could complicate the interpretation of the effect of ouabain or ECG on Src activity. The autophosphorylation level of Src at Tyr418 (pY418), as an indication of Src activation, was detected using the anti-pY418 antibody (Invitrogen).

Cell Lines and Cell Culture. Porcine renal epithelial cells LLCPK1 (ATCC®CL-101 ${ }^{\mathrm{TM}}$ ), a stable cell line established from LLC-PK1 with Na/K-ATPase $\alpha 1$-specific knockdown (PY-17) (Liang et al., 2006), and a cell line established from PY-17 expressing Na/K-ATPase $\alpha 2$ in lieu of $\alpha 1$ (LX- $\alpha 2)$ (Xie et al., 2015a) were cultured in Dulbecco's modified Eagle's medium in 10\% FBS, 100 units $/ \mathrm{ml}$ penicillin, and $100 \mu \mathrm{g} / \mathrm{ml}$ streptomycin in a $5 \% \mathrm{CO}_{2}$ humidified incubator.

Simulated Hypoxia/Reoxygenation and ECG In Vitro. Ischemia was simulated in cells by placement of a glass LifterSlip (ThermoFisher Scientific) over the monolayers and removal of substrate, as modified from previously described procedures (Pittts and Tombs, 2004). Briefly, a $22 \times 22 \mathrm{~mm}$ LifterSlip (ThermoFisher Scientific) was delicately placed over the cell monolayer in one well of a six-well plate, resulting in coverage of about $50 \%$ of the well. Reperfusion was simulated by gently removing the LifterSlip. In addition, substrate removal was performed to mimic I/R as described (Belliard et al., 2013). 
A

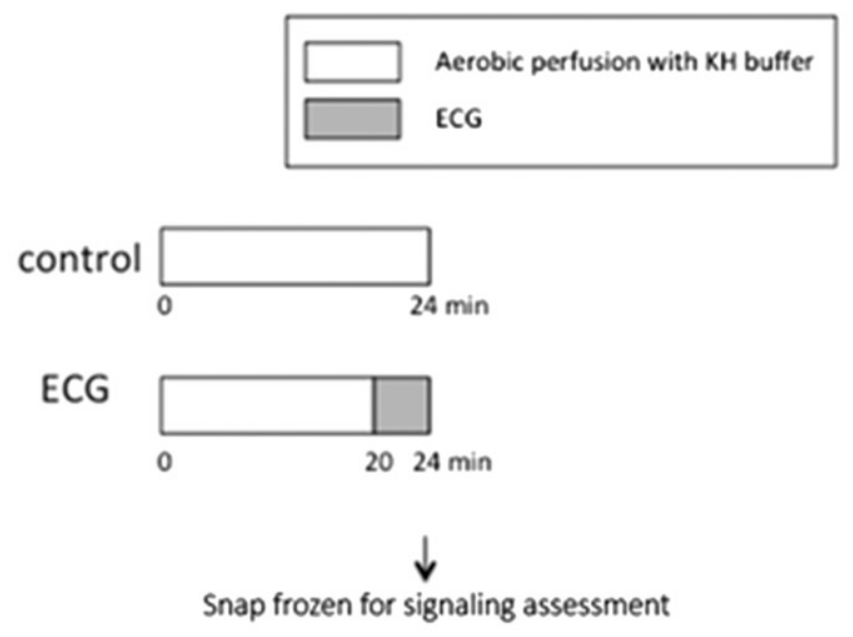

B
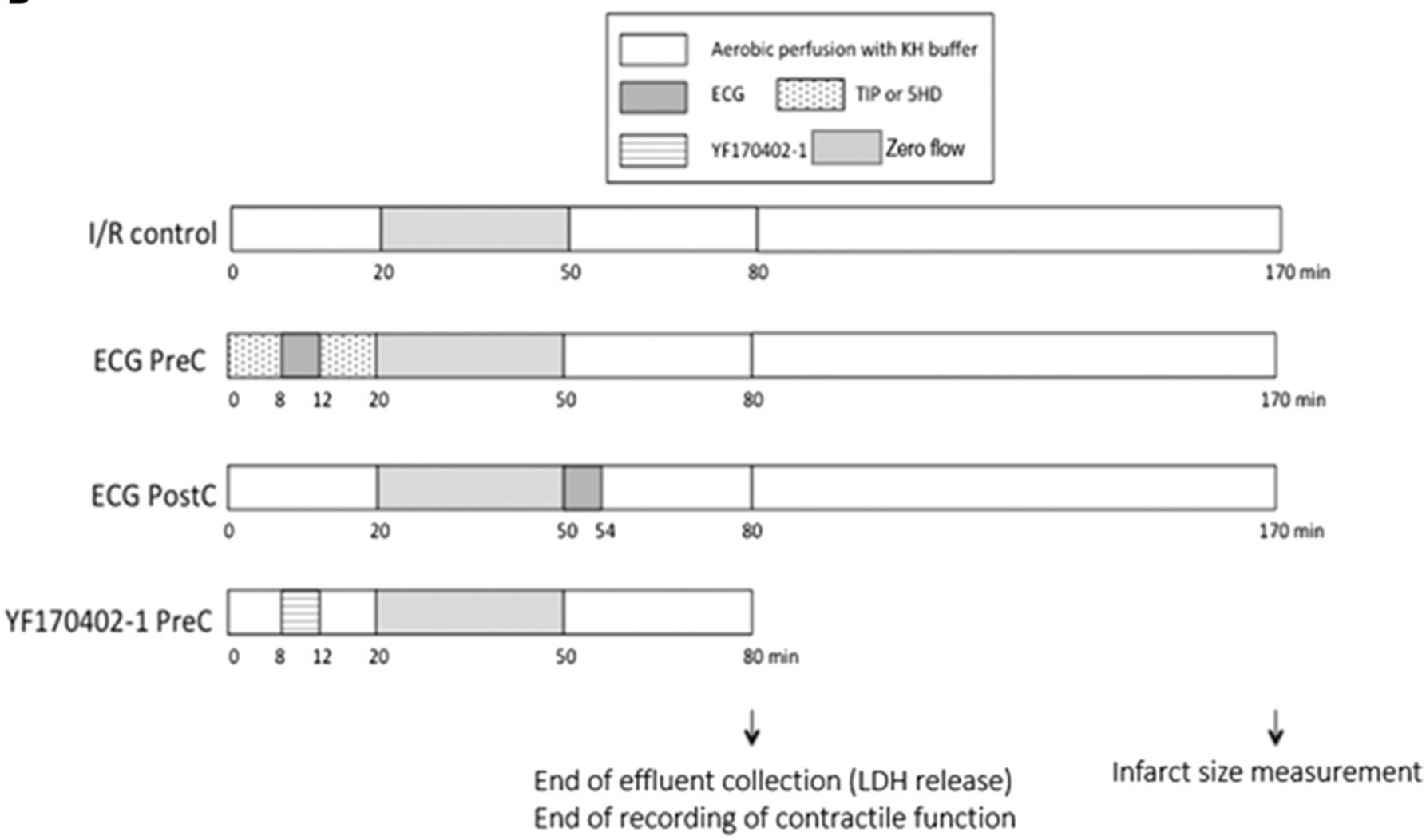

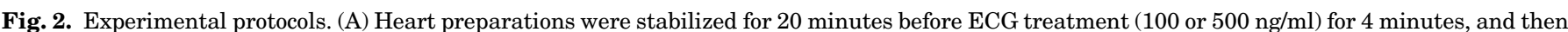

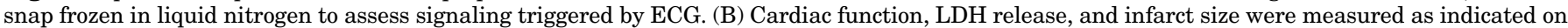

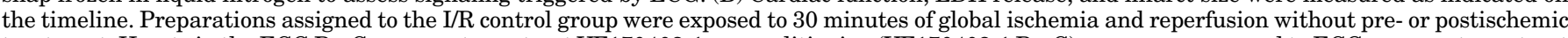

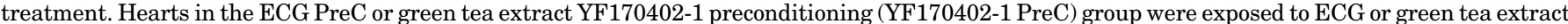

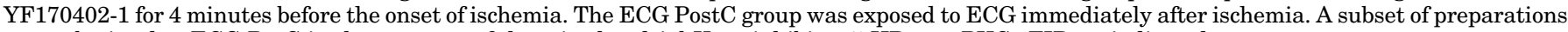
was submitted to ECG PreC in the presence of the mitochondrial $\mathrm{K}_{\mathrm{ATP}}$ inhibitor 5-HD or a PKC $\mathrm{TIP}$, as indicated.

Lactate Dehydrogenase Activity. The amount of LDH released was used as an indicator of loss of cellular integrity. At the end of the simulated reperfusion, cell media were collected and LDH activity was determined colorimetrically using a standard assay (Cytotoxicity Detection Kit; Roche Applied Science). To evaluate the extent of the injury as a percentage of the total cell population, $\mathrm{LDH}$ was measured in a subset of experiments in lysates obtained by treatment of the monolayer with $0.1 \%$ Triton $\mathrm{X}-100$ at $4^{\circ} \mathrm{C}$ for 30 minutes at the end of the protocol. Total LDH was obtained as the sum of $\mathrm{LDH}$ released in the media and $\mathrm{LDH}$ in the cell lysates (Belliard et al., 2013).
Isolated Rat Heart Preparation. Rat hearts were prepared for Langendorff perfusion and I/R as previously described (Pierre et al., 2007; Li et al., 2008). Briefly, hearts from 11- to 12 -week-old male Sprague-Dawley rats were rapidly excised and retrogradely perfused through the aorta using a nonrecirculating Langendorff apparatus. Krebs-Henseleit (KH) buffer consisted of $\mathrm{NaCl}, 118 \mathrm{mM}$; $\mathrm{KCl}, 4.7 \mathrm{mM}$; $\mathrm{MgSO}_{4}, 0.8 \mathrm{mM} ; \mathrm{CaCl}_{2}, 1.3 \mathrm{mM} ; \mathrm{NaHCO}_{3}, 25.0 \mathrm{mM} ; \mathrm{KH}_{2} \mathrm{PO}_{4}, 1.2 \mathrm{mM}$; EGTA, $0.3 \mathrm{mM}$; and glucose, $11.0 \mathrm{mM}$. The buffer was saturated with $95 \% \mathrm{O}_{2}-5 \% \mathrm{CO}_{2}\left(\mathrm{pH} 7.4,37^{\circ} \mathrm{C}\right)$. Hearts were perfused at a constant flow of about $15 \mathrm{ml} / \mathrm{min}$, which resulted in a coronary perfusion pressure of about $100 \mathrm{~mm} \mathrm{Hg}$ at the beginning of the experiment. A 
A
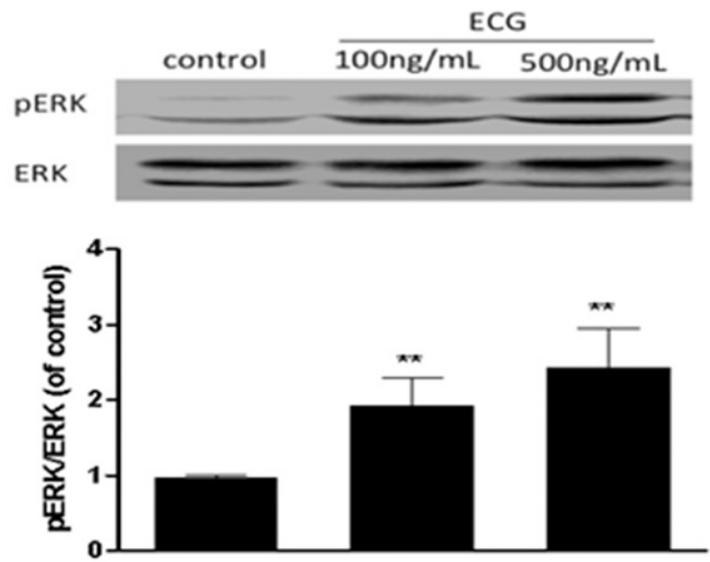

control

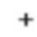

$+$

$+$

ECG-100ng/mL

ECG-500ng/mL

B
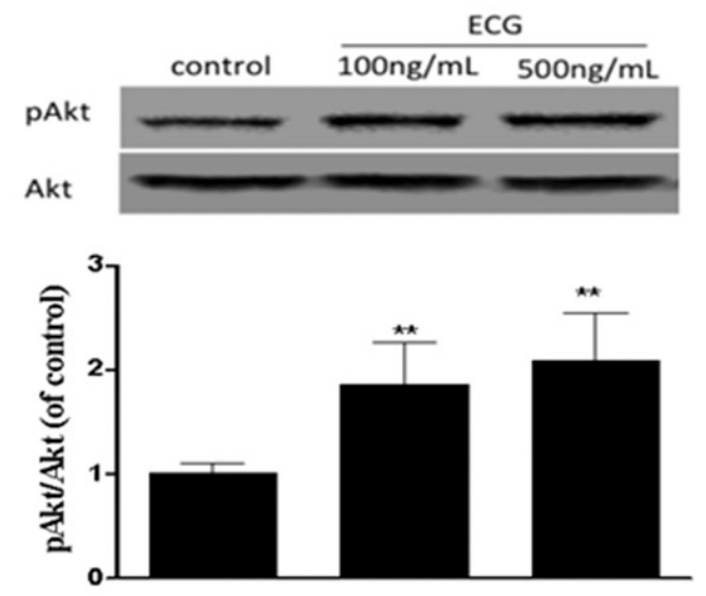

control

ECG-100ng/mL

ECG-500ng/mL
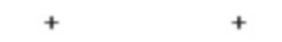

$-$

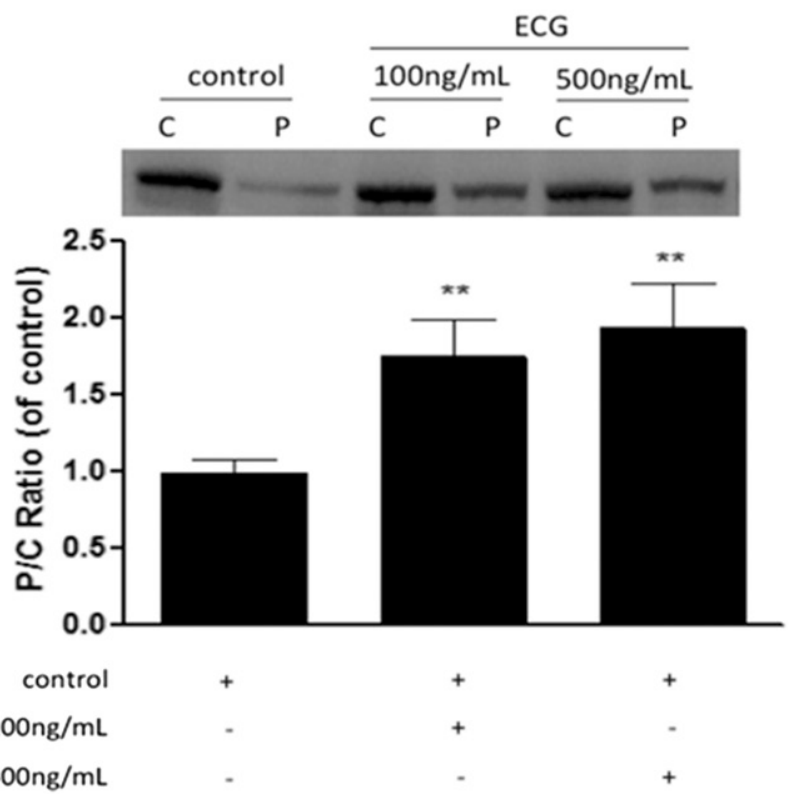

water-filled latex balloon-tipped catheter was inserted into the left ventricle and adjusted to a left ventricular end diastolic pressure of about $5 \mathrm{~mm} \mathrm{Hg}$ during the initial equilibration. Hearts were paced at $4.5 \mathrm{~Hz}$ throughout the experiment except during ischemia. The contractile performance of the isolated rat heart was assessed by the left ventricular developed pressure (LVDP). All hearts were stabilized for 25 minutes and then subjected to one of the experimental protocols described in Fig. 2. Experimental procedures were conducted in accordance with the Guide for the Care and Use of Laboratory Animals (National Institutes of Health Publication, 8th Edition, 2011, https:// www.ncbi.nlm.nih.gov/books/NBK54050/ doi: 10.17226/12910) and approved by the Anhui Agricultural University Animal Care and Use Committee.

Experimental Protocols. After stabilization, hearts used to test ECG-induced signaling were exposed to protocol A (Fig. 2). Specifically, they were perfused with 100 or $500 \mathrm{ng} / \mathrm{ml}$ ECG for 4 minutes and snap frozen in liquid nitrogen. Hearts used to test the protective effects of ECG-based intervention were exposed to protocol B (Fig. 2). Specifically, hearts in the I/R group were perfused with $\mathrm{KH}$ buffer for 20 minutes, subjected to 30 -minute zero-flow ischemia, and reperfused for up to 120 minutes. To determine the PreC effect of ECG, hearts were perfused with normal $\mathrm{KH}$ buffer for 8 minutes, exposed to ECG $(10,50,100$, or $500 \mathrm{ng} / \mathrm{ml})$ for 4 minutes, followed by 8 minutes of washout, and then subjected to 30 minutes of global ischemia and 120 minutes of reperfusion. The PreC effect of green tea extract YF170402-1 (see supplemental methods and supplemental figure 3) was also tested using this protocol. To determine the PostC effect of ECG, hearts were perfused with $\mathrm{KH}$ buffer for 20 minutes and then subjected to 30 minutes of global ischemia. At the onset of reperfusion, hearts were perfused with ECG $(100 \mathrm{ng} / \mathrm{ml})$ for 4 minutes, and the perfusion continued with normal KH buffer for up to 120 minutes. To test whether the PreC effect of ECG requires the activation of PKC $\varepsilon$ and the opening of the mitochondrial $\mathrm{K}_{\mathrm{ATP}}$ channel, hearts after stabilization were perfused with $\mathrm{PKC} \varepsilon$ translocation-specific inhibitor peptide or mitochondrial $\mathrm{K}_{\mathrm{ATP}}$ channel blocker 5-HD for 20 minutes, followed by 30 -minute zero-flow ischemia and 120 -minute reperfusion.

Lactate Dehydrogenase Release and Infarct Size. These assays were performed as we have previously described (Pierre et al., 2007). Coronary effluents were collected during the initial 30 minutes of reperfusion and LDH was measured using the TOX7 kit from Sigma Chemical Co. To measure infarct size, hearts were collected following 120 minutes of reperfusion and frozen at $-20^{\circ} \mathrm{C}$ for 2 hours. Each heart was cut into five 3-mm-thick transverse sections and incubated in a triphenyltetrazolium chloride solution (1\% in phosphate buffer, $\mathrm{pH} 7.4$ ) at $37^{\circ} \mathrm{C}$ for 20 minutes, and then further incubated in formalin for another 20 minutes. Infarct size was assessed as we previously described (Pierre et al., 2007).

Na/K-ATPase Activity. One hundred milligrams of powdered left ventricle were suspended in $10 \mathrm{ml}$ of $1 \mathrm{M} \mathrm{KCl}$ solution and homogenized with a MT-30k tissue homogenizer (Mi Ou, Taizhou, China) for 30 seconds. The homogenate was centrifuged at $1000 \mathrm{~g}$ for 10 minutes. The sediment was suspended in $10 \mathrm{ml}$ of a solution of $50 \mathrm{mM} \mathrm{KCl}$ and $50 \mathrm{mM}$ Tris $\mathrm{HCl}(\mathrm{pH} \mathrm{7.4})$ and washed twice with $1 \mathrm{ml}$ $50 \mathrm{mM}$ Tris $\mathrm{HCl}$ ( $\mathrm{pH}$ 7.4). The final pellet was suspended in $1 \mathrm{ml}$ TrisEDTA ( $\mathrm{pH}$ 7.4) and homogenized again with the MT-30k homogenizer for 30 seconds. All procedures were conducted on ice and

Fig. 3. ECG-induced cardioprotective signaling. After stabilization, Langendorff- perfused rat heart preparations were exposed to 4 minutes of ECG (100 or $500 \mathrm{ng} / \mathrm{ml}$ ), and then quick frozen in liquid nitrogen (Fig. 2A). Crude homogenates were assayed for total and phosphorylated forms of ERK (A) and Akt (B), or further processed for analysis of cytosolic and particulate $\mathrm{PKC} \varepsilon$ as described in Materials and Methods (C). Upper panels: representative immunoblots. Lower panels: activation expressed as ratios of phosphorylated-to-total forms (ERK and Akt) or as ratios of particulate-to-cytosolic (PKC $\varepsilon$ ), normalized to control (untreated). Values are mean \pm S.E.M. of five independent experiments for each condition. ${ }^{* *} P<0.01$ vs. control (untreated). C, cytosolic; $\mathrm{P}$, particulate. 
A

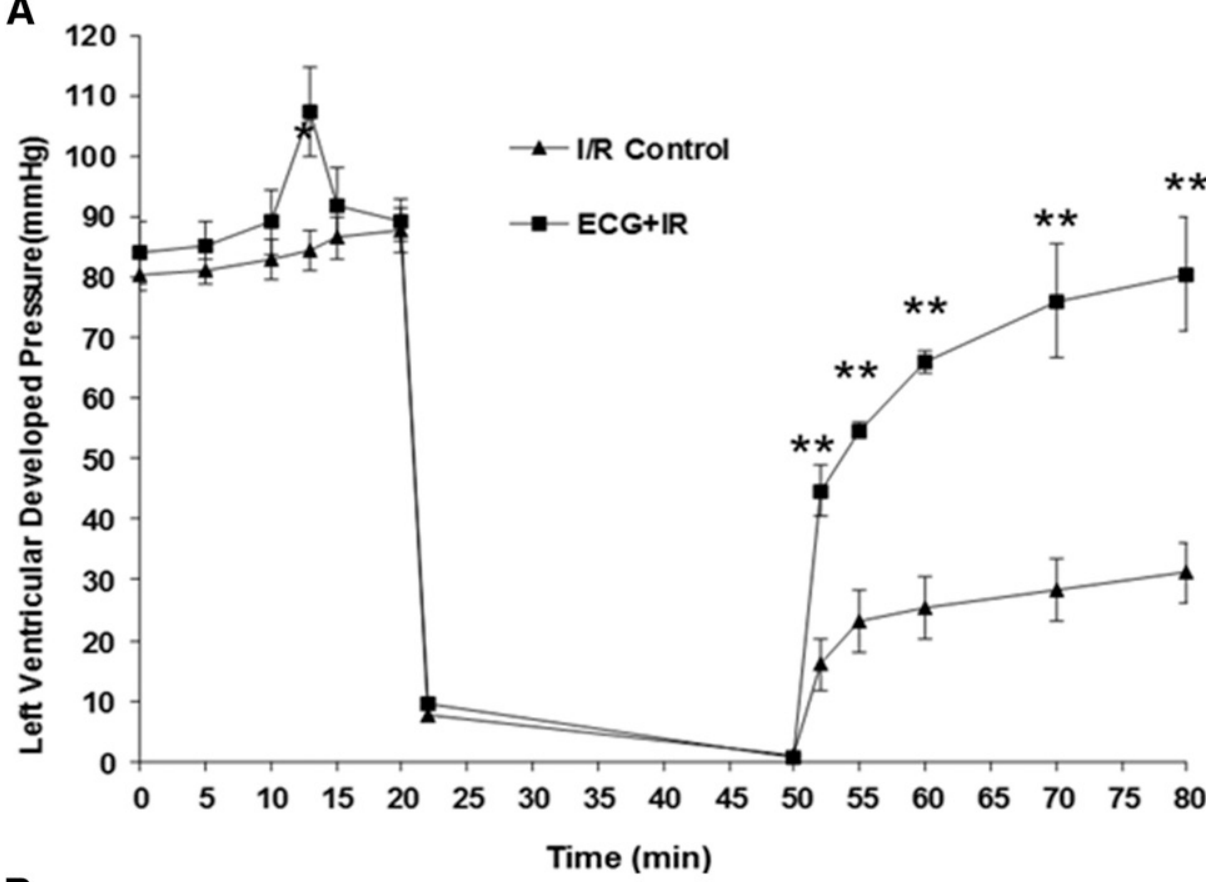

B

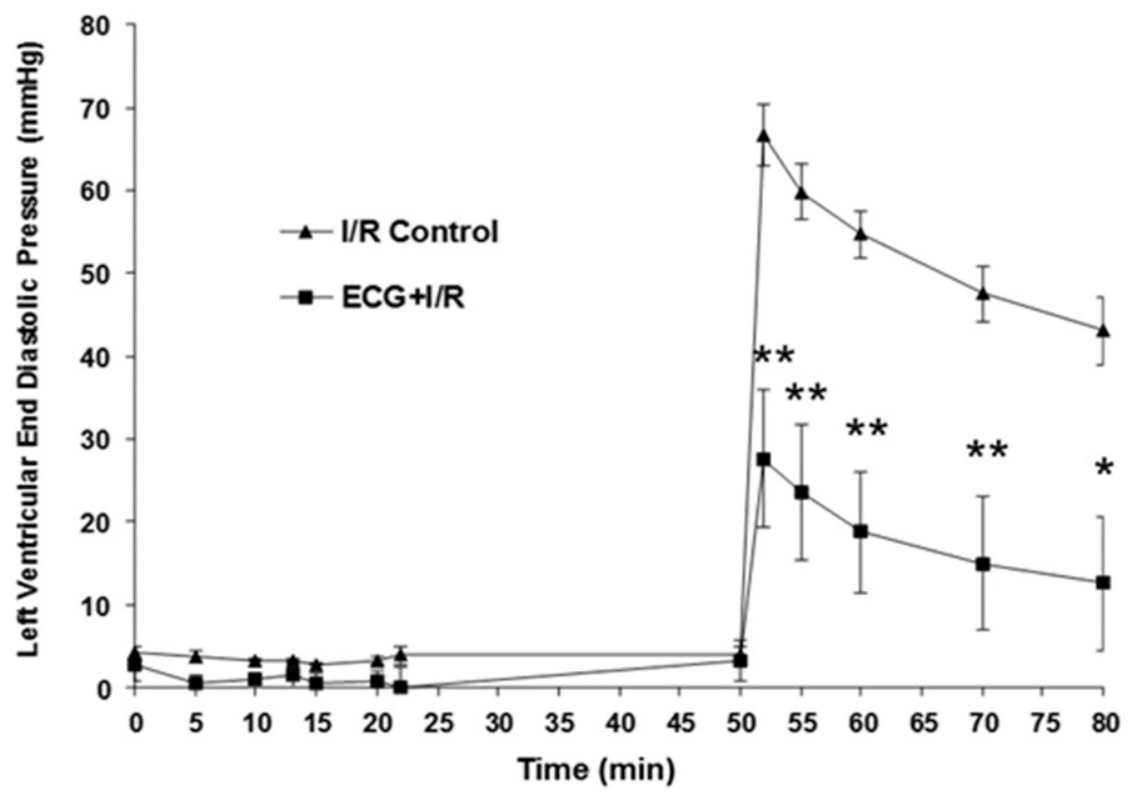

Fig. 4. Effect of ECG PreC on myocardial function. Langendorff-perfused rat heart preparations were exposed to the ECG PreC protocol shown in Fig. 2B. ECG was used at the concentration of $500 \mathrm{ng} / \mathrm{ml}$. Time-dependent recovery of LVDP (A) and left ventricular end diastolic pressure (B) are shown in comparison with the I/R group (control). Values are mean \pm S.E.M. of five to seven preparations in each group. ${ }^{*} P<0.05 ; * * P<0.01$ vs. I/R control. centrifugation was conducted at $4^{\circ} \mathrm{C}$. Before activity measurements, the crude homogenates were incubated with alamethicin $(0.5 \mathrm{mg} /$ $\mathrm{mg}$ protein) for 10 minutes at $25^{\circ} \mathrm{C}$. The alamethicin treatment ensures that the substrates can bind to the ATP site in closed membrane vesicles. $\mathrm{Na} / \mathrm{K}$-ATPase activity was measured as the difference in inorganic phosphate released by using the assay kit (A070-2) according to the manufacturer's protocol (Nanjing Jiancheng Bioengineering Institute, Nanjing, China), in the presence or absence of a saturating concentration of ouabain as previously described (Zhao et al., 2013). The activity was measured in triplicate for each heart.

Cytosolic and Particulate Fractions. One hundred milligrams of powdered left ventricle were suspended in $300 \mu$ l buffer A containing EGTA, $10 \mathrm{mM}$; EDTA, $1 \mathrm{mM}$; dithiothreitol, $0.5 \mathrm{mM}$; and

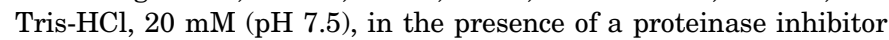
cocktail (BestBio, Shanghai, China). The solution was homogenized using the MT-30k homogenizer (Mi Ou, Hangzhou, China) for 30 seconds on ice and then centrifuged at $100,000 \mathrm{~g}$ for 1 hour at $4^{\circ} \mathrm{C}$. The supernatants were collected as cytosolic fractions. The pellets were suspended in buffer A with $1 \%$ Triton 100, homogenized with the MT$30 \mathrm{k}$ homogenizer for 30 seconds, and then centrifuged at 25,000g for 10 minutes at $4^{\circ} \mathrm{C}$. The supernatants were designated as particulate fractions ( $\mathrm{Li}$ et al., 2008).

Sample Preparation for Western Blotting. Forty mg of left ventricle were frozen in $1 \mathrm{ml}$ of liquid nitrogen-chilled acetone containing $10 \%$ trichloroacetic acid $10 \%(\mathrm{w} / \mathrm{v})$. After overnight incubation with $10 \% \mathrm{TCA}$ at $-80^{\circ} \mathrm{C}$, the samples were washed with acetone for 20 minutes on a shaker and then centrifuged at $10,000 \mathrm{~g}$ for 10 minutes at $4^{\circ} \mathrm{C}$. The wash procedure was repeated twice. The pellets were homogenized in SDS and centrifuged at $14,000 \mathrm{~g}$ for 10 minutes at room temperature. The supernatant was collected and stored at $-80^{\circ} \mathrm{C}$ until western blot analysis (Xie et al., 2015b).

Western Blot. Equal amounts of denatured proteins were separated by $10 \%$ SDS-PAGE and transferred to nitrocellulose membranes. The 
TABLE 1

Functional parameters in Langendorff-perfused rat hearts submitted to ischemia/reperfusion with or without pre/post ECG conditioning Values are mean \pm S.E.M. of four to six rats/group. Preconditioning was induced with ECG $500 \mathrm{ng} / \mathrm{ml}$ and postconditioning with ECG $100 \mathrm{ng} / \mathrm{ml}$ as shown in Figs. 4 and 6.

\begin{tabular}{|c|c|c|c|c|c|c|}
\hline \multirow{2}{*}{ Parameter } & \multicolumn{2}{|c|}{ Control } & \multicolumn{2}{|c|}{ Preconditioning ECG } & \multicolumn{2}{|c|}{ Postconditioning ECG } \\
\hline & Before I/R & After I/R & Before I/R & After I/R & Before I/R & After I/R \\
\hline $\mathrm{dp} / \mathrm{dt}_{\max }(\mathrm{mm} \mathrm{Hg} / \mathrm{s})$ & $1475.3 \pm 114.3$ & $542.8 \pm 112.6$ & $1310.2 \pm 53.0$ & $1238.5 \pm 251.8^{*}$ & $1514.0 \pm 133.2$ & $1331.3 \pm 142.5^{* *}$ \\
\hline $\mathrm{dp} / \mathrm{dt}_{\min }(\mathrm{mm} \mathrm{Hg} / \mathrm{s})$ & $-1130.9 \pm 47.6$ & $-363.7 \pm 50.5$ & $-1137.2 \pm 89.9$ & $1044.5 \pm 112.3^{* *}$ & $1033.7 \pm 127.8$ & $848.3 \pm 141.0 *$ \\
\hline LVESP (mm Hg) & $84.9 \pm 3.1$ & $76.1 \pm 8.4$ & $89.6 \pm 3.8$ & $93.7 \pm 3.7$ & $84.3 \pm 5.8$ & $94.7 \pm 11.3$ \\
\hline LVEDP (mm Hg) & $3.2 \pm 0.2$ & $41.5 \pm 3.7$ & $1.2 \pm 0.9$ & $12.3 \pm 7.5^{*}$ & $6.3 \pm 3.2$ & $22.3 \pm 6.4^{*}$ \\
\hline LVDP (mm Hg) & $85.1 \pm 3.2$ & $35.0 \pm 5.0$ & $88.2 \pm 4.6$ & $81.3 \pm 8.7^{* *}$ & $78.0 \pm 4.6$ & $72.3 \pm 10.1^{*}$ \\
\hline
\end{tabular}

$\mathrm{dP} / \mathrm{dt}_{\max }$, rate of pressure development; $\mathrm{dP} / \mathrm{dt}_{\min }$, rate of pressure decline; LVEDP, left ventricle end diastolic pressure; LVESP, left ventricle end systolic pressure. ${ }^{*} P<0.05 ; * * P<0.01$ vs. I/R control.

membranes were blocked with 5\% skimmed milk in PBS with Tween 20 solution for 1 hour (room temperature), washed with PBS with Tween 20, and incubated with primary antibodies against PKCe (sc214; Santa cruz, CA), p-Src (phospho-Y418), Src (ab4816 and ab47405, respectively; Abcam, Shanghai, China), phosphorylated extracellular signal-regulated kinase (p-ERK) and ERK (4370 and 4695, respectively; Cell Signaling Technology, Danvers, MA), and phosphorylated protein kinase B (p-Akt) and Akt (4060 and 9272, respectively; Cell Signaling Technology, Danvers, MA), gently shaking overnight at $4^{\circ} \mathrm{C}$. The membranes were further washed with PBS with Tween 20 three times and then incubated with secondary antibodies of anti-rabbit IgG (7074; Cell Signaling Technology, Danvers, MA) for 1 hour at room temperature. Protein bands were detected using an Enhanced Chemiluminescence Detection Kit (Vazyme Biotech, Nanjing, China) for 3 minutes. Protein band intensities were analyzed using the ChemicDoc MP Imaging System with the Image Laboratory System (Bio-Rad, Hercules, CA).

Statistical Analysis. Results are expressed as mean \pm S.E.M. Data were analyzed by one-way ANOVA followed by Tukey's post hoc test unless otherwise stated. A difference was considered significant for $P<0.05$

\section{Results}

Effects of ECG on Purified Pig Kidney Na/K-ATPase Preparations. The effect of ECG on Na/K-ATPase was tested in highly purified preparations from pig kidney. As shown in Fig. 1A, the expected dose-dependent inhibition was observed, with an $\mathrm{IC}_{50}$ value of about $5 \mu \mathrm{M}$, within the range previously reported by Ochiai et al. (2009) under similar conditions $(0.8 \mu \mathrm{M})$. To assess a possible modulatory effect of ECG on the Na/K-ATPase/Src receptor function, the cell-free system first reported by Tian et al. (2006) was used. In this experiment, the ratio of Src phosphorylated at Y418/total Src signal in purified recombinant Src preparations was assessed by western blotting as an indicator of Src kinase activation by autophosphorylation. As reported by Tian et al. (2006), addition of purified pig kidney $\mathrm{Na} / \mathrm{K}$-ATPase alone substantially decreased this ratio by decreasing Src phosphorylation to a nearly undetectable level (Fig. 1B, first lane). Importantly, $\mathrm{Na} / \mathrm{K}-\mathrm{ATP}$ ase activity was inhibited by addition of vanadate in all assay tubes as previously described (Tian et al., 2006). This ensured that changes in ATP availability to Src secondary to ouabain and/or ECG effect on ATP hydrolysis by Na/K-ATPase would not complicate the interpretation. As expected, based on the Tian-Xie model of binary regulation of Src by Na/K-ATPase (Tian et al., 2006), the pSrc/Src ratio increased upon addition of ouabain $(10 \mu \mathrm{M}$, for 15 minutes) in the presence of $\mathrm{Na} /$ K-ATPase (Fig. 1B, second lane). The ratio obtained under these experimental conditions was set as the $100 \%$ value, and the ratios obtained for all other experimental conditions tested were normalized to this ratio. In this system, we observed that ouabain-induced activation was slightly but significantly reduced in the presence of $5 \mu \mathrm{M}$ ECG (Fig. 1B, third lane), and that this concentration of ECG itself was able to activate Src in the absence of ouabain (Fig. 1B, fourth lane). Taken together, these observations suggest that ECG-induced modulation of $\mathrm{Na} / \mathrm{K}$-ATPase conformation affects both enzyme activity and $\mathrm{Na} / \mathrm{K}$-ATPase/Src receptor activation status in a CTS-like manner.

ECG-Induced Signaling in the Rat Heart. We have previously shown that $1 \mu \mathrm{g} / \mathrm{ml}$ ECG stimulates PKC $\varepsilon$ (Li et al., 2008). To further assess this property within a physiologic range and explore possible effects on additional known targets of the cardiac Na/K-ATPase pathway, we exposed Langendorff-perfused rat heart preparations to 100 and $500 \mathrm{ng} / \mathrm{ml} \mathrm{ECG} \mathrm{(442.4} \mathrm{mol.} \mathrm{wt.,} \mathrm{corresponding} \mathrm{to}$ 0.226 and $1.13 \mu \mathrm{M}$, respectively) for 4 minutes using the protocol described in Fig. 2A. Phosphorylation of ERK, Akt and $\mathrm{PKC} \varepsilon$ was assessed by western blotting as indicators of kinase activation as described in Materials and Methods. As shown in Fig. 3, a dose-dependent CTS-like effect was observed for all three kinases at the tested concentrations.

Cardiac Pre- and Postconditioning with ECG. We next tested whether ECG could protect the heart from I/R

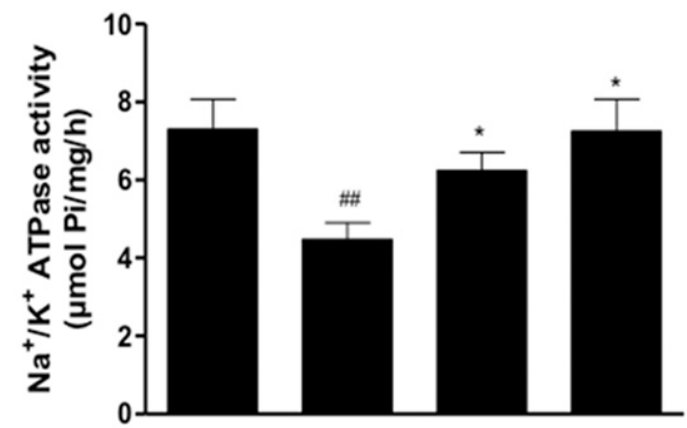

$$
\begin{array}{rrrrr}
\text { control } & + & - & - & \text { - } \\
\text { I/R control } & - & + & + & + \\
\text { PreC-ECG-100ng/mL } & - & - & + & \\
\text { PreC-ECG-500ng/mL } & - & - & & +
\end{array}
$$

Fig. 5. Effect of ECG PreC ( 100 or $500 \mathrm{ng} / \mathrm{ml}$ ) on Na/K-ATPase activity in rat left ventricular tissue. Hearts were exposed to ECG PreC protocol as described in Fig. 2B. Values are mean \pm S.E.M. of four independent experiments for each group. ${ }^{\# \#} P<0.01$ vs. control; ${ }^{*} P<0.05$ vs. I/R control. 
injury. Given the positive inotropic effect of ECG, we opted for the PreC protocol depicted in Fig. 2B, which includes an 8minute washout before the onset of ischemia. We have previously used this protocol in our studies of the preconditioning effect of the positive inotrope ouabain ((Pierre et al., 2007)) to limit confounding effects. As shown in Fig. 4A, 4 minutes of exposure to ECG $(500 \mathrm{ng} / \mathrm{ml})$ produced the expected significant increase in contractility and subsequent recovery to baseline during the 8 -minute washout. Thirty minutes of zero-flow ischemia resulted in cardiac arrest in both control and ECG-treated hearts. Although cardiac contraction resumed after reperfusion, it was significantly depressed, with reduced left ventricular end systolic pressure and increased left ventricular end diastolic pressure in $\mathrm{I} / \mathrm{R}$ rat hearts (Table 1). At the end of 30-minute reperfusion, ECG PreC $(500 \mathrm{ng} / \mathrm{ml})$ increased the LVDP recovery from $41 \%$ of preischemia in the I/R heart to $92 \%(* * P<0.01)$ (Fig. 4; Table 1). As illustrated in Supplemental Fig. 1, the protective effect of ECG on cardiac performance was detected at a concentration as low as $10 \mathrm{ng} / \mathrm{ml}$ and was near maximal at $50 \mathrm{ng} / \mathrm{ml}$. In addition, a group of hearts was treated with ECG $(500 \mathrm{ng} / \mathrm{ml})$ for the entire 12 minutes without washout and then subjected to I/R. This protocol produced the same degree of LVDP recovery as the 4-minute exposure (data not shown). As shown in Fig. 7, the improved functional recovery provided by ECG PreC was accompanied by significant reduction in infarct size by about $40 \%$ and dose-dependent reduction of $\mathrm{LDH}$ release, indicative of reduced myocardial cell death. Like ischemic preconditioning or ouabain preconditioning, ECG PreC (100 and $500 \mathrm{ng} / \mathrm{ml}$ ) protected myocardial $\mathrm{Na} / \mathrm{K}$-ATPase against I/R-induced alteration (Fig. 5).

Because the onset of a heart attack is unpredictable, PostC protocols that trigger cardioprotective signaling at reperfusion are more applicable in the context of acute myocardial infarction and can potentially reduce reperfusion injury during percutaneous interventions. The protective effect of an ECG-based PostC protocol was tested at a concentration of $100 \mathrm{ng} / \mathrm{ml}$ ECG, which was based on the maximal level of protection that this concentration provided when applied in the ECG PreC protocol (Supplemental Fig. 1). As depicted in Fig. 2B, ECG was given at the onset of reperfusion for 4 minutes. This treatment provided significant protection of contractile function (Fig. 6) and reduction of $\mathrm{LDH}$ release (Fig. 7A) and infarct size (Fig. 7B), which were comparable to the protection provided by ECG PreC. Taken together, these data suggest that ECG is an effective pharmacological pre- and postconditioner at concentrations observed in humans after consumption of one to two cups of green tea.

Involvement of PKC $\varepsilon$ and Mitochondrial $\mathrm{K}_{\mathrm{ATP}}$ Channel in ECG PreC. We have shown that TIP, a PKC $\varepsilon$-specific translocation inhibitor, effectively blocks ECG-induced PKC $\varepsilon$ activation and the subsequent increase in contractility in Langendorff-perfused rat hearts (Li et al., 2008). We applied the same approach to assess whether activation of PKC $\varepsilon$ is involved in ECG-induced preconditioning of the heart, using the protocol described in Fig. 2. Blockage of PKC $\varepsilon$ activation with TIP abolished cardioprotection by ECG PreC, as indicated by the blunted functional recovery, $\mathrm{LDH}$, and infarct (Supplemental Fig. 2). We further applied this pharmacological approach to test whether $5-\mathrm{HD}$, a mitochondrial $\mathrm{K}_{\mathrm{ATP}}$ channel blocker, could reduce ECG-induced protection as previously observed for most forms of PreC. As shown in Supplemental Fig. 2, bracketing the 4 minutes of ECG perfusion prior to ischemia with 5-HD resulted in a clear reduction in LVDP recovery and increased $\mathrm{LDH}$ release post I/R. These are strongly suggestive of involvement of mitochondrial $\mathrm{K}_{\mathrm{ATP}}$ channel opening in cardioprotective signaling by ECG.

Role of $\mathrm{Na} / \mathrm{K}$-ATPase in ECG-Mediated Protection against I/R. The role of $\mathrm{Na} / \mathrm{K}$-ATPase $\alpha 1$ in ECG-mediated protection was tested using the only mammalian cell model with a drastically reduced level of $\mathrm{Na} / \mathrm{K}$-ATPase $\alpha 1$ protein expression. This stable cell line (PY-17) was established using the LLC-PK1 pig renal epithelial cell line as the parental line and small interfering RNA (Liang et al., 2006). We then applied the in vitro protocol of simulated hypoxia/reoxygenation that we have previously modified from (Pittts and Tombs, 2004) as described in Pierre et al. (2011). As shown in Fig. 8A, ECG protected Na/K-ATPase $\alpha 1$-expressing LLC-PK-1 but not the $\mathrm{Na} / \mathrm{K}$-ATPase $\alpha 1$ knockdown cells (expressing about $15 \%$ of $\mathrm{Na} / \mathrm{K}$-ATPase $\alpha 1$ ). Further evaluation in this model revealed that unlike $\mathrm{PKC} \varepsilon$ activation induced by the CTS ouabain, $\mathrm{Na} / \mathrm{K}$-ATPase presence was not required for ECGinduced PKCe translocation (Fig. 8B). Finally, in the PY-17 rescue line LX- $\alpha 2$, which expresses the $\alpha 2$ isoform of $\mathrm{Na}$ / $\mathrm{K}$-ATPase and therefore has normal $\mathrm{Na} / \mathrm{K}$-ATPase ion transport but no Na/K-ATPase/Src receptor function (Xie et al., 2015a), we observed that ECG failed to trigger protection against I/R (Fig. 8C).

Preconditioning by Green Tea Extract YF170402-1. We next tested whether a green tea extract containing 100-500 ng/ml of ECG would recapitulate the protection provided by 100-500 ng/ml of ECG alone. As shown in Supplemental Fig. 3, the weight percentage of major catechins in green tea extract YF170402-1, quantified using high-performance liquid chromatography as described in the Supplemental Material, indicated an ECG content of $7.91 \%$ (Supplemental Fig. 3). Accordingly, a PreC protocol (Fig. 2B) was applied using $1500 \mathrm{ng} / \mathrm{ml} \mathrm{YF170402-1} \mathrm{to} \mathrm{provide} \mathrm{about} 120 \mathrm{ng} / \mathrm{ml}$ of ECG in our ex vivo system. As shown in Supplemental Fig. 3, YF170402-1 preconditioning allowed for functional recovery of about $80 \%$, in good correlation with the recovery observed after preconditioning with ECG $100 \mathrm{ng} / \mathrm{ml}$ alone using this $\mathrm{I} / \mathrm{R}$ protocol (Fig. 2B). This result does not support a role of synergistic or antagonistic interactions among green tea catechins in the protection. However, it does clearly suggest that ECG may play a more significant role than initially thought in the beneficial effect of green tea consumption.

\section{Discussion}

Consumption of green tea, the richest dietary source of ECG, is associated with reduced risk of cardiac mortality (Higdon and Frei, 2003). The abundantly reported antioxidant effects of ECG and other tea polyphenols, which typically occur at concentrations over $10 \mu \mathrm{M}$, are well above dietary levels. Therefore, those properties are unlikely to contribute to any health benefits associated with green tea consumption, and the mechanism underlying the cardioprotective effect of green tea remains incompletely understood. At concentrations that are commonly detected in humans after consumption of 


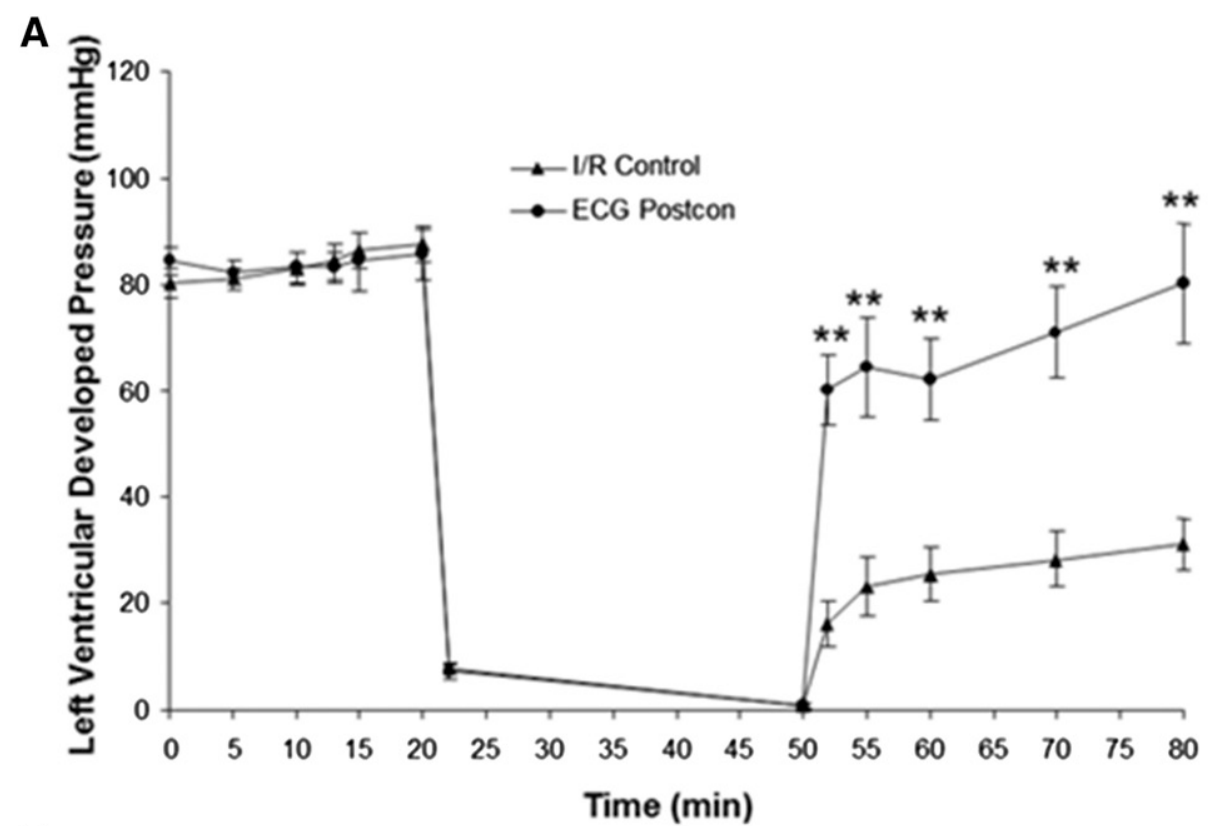

B

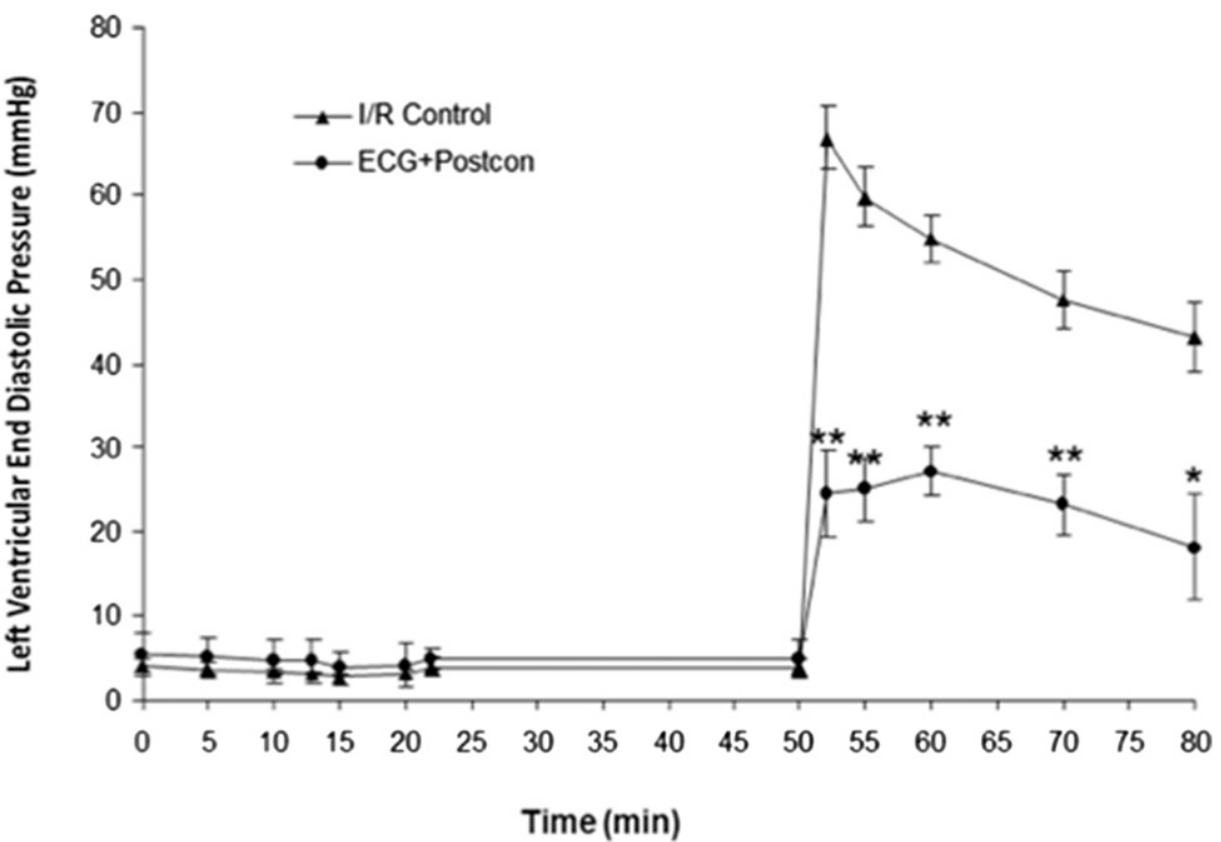

Fig. 6. Effect of ECG PostC on myocardial function. Langendorff-perfused rat heart preparations were exposed to the ECG $(100 \mathrm{ng} / \mathrm{ml})$ PostC protocol shown in Fig. 2B. Time-dependent recovery of LVDP (A) and left ventricular end diastolic pressure (EDP) (B) are shown in comparison with the I/R group (control). Values are mean \pm S.E.M. of five to seven rat hearts in each group. ${ }^{* *} P<0.01$ vs. I/R control. a cup of tea (Fung et al., 2013), ECG has been shown to induce cellular events that include activation of cardiac $\mathrm{PKC} \varepsilon(\mathrm{Li}$ et al., 2008) and modulation of $\mathrm{Na} / \mathrm{K}$-ATPase conformation and activity (Ochiai et al., 2009). At least theoretically, these properties could confer ECG has a CTS-like ability to activate the $\mathrm{Na} / \mathrm{K}$-ATPase-dependent signaling pathway and trigger cardioprotection against ischemia/reperfusion injury through Src and PKC $\varepsilon$. Accordingly, this study examined whether dietary concentrations of ECG could 1) activate the Na/K-ATPase/Src receptor in a cell-free system, 2) activate a CTS-like signaling pathway in cardiac tissue, and 3) trigger $\mathrm{PKC} \varepsilon$-dependent protection against cardiac ischemia/reperfusion injury in Langendorff-perfused rat heart preparations. These were further complemented by follow-up mechanistic studies using the only mammalian system with a near-null expression level of $\mathrm{Na} / \mathrm{K}$-ATPase $\alpha 1$ to specifically assess its role in ECGmediated protection.

In cell-free experiments (Fig. 1), studies of $\mathrm{Na} / \mathrm{K}$-ATPase activity confirmed a modulatory role of ECG on the enzyme conformation and activity within the submicromolar range (Fig. 1A), as first suggested by Ochiai et al. (2009) in a classic $\mathrm{Na} / \mathrm{K}$-ATPase-enriched pig kidney preparation. As a modulator of $\mathrm{Na} / \mathrm{K}$-ATPase $\alpha 1$ conformation, ECG is a candidate modulator of the $\mathrm{Na} / \mathrm{K}$-ATPase/Src receptor function (Ye et al., 2011), and therefore a potential trigger of $\mathrm{Na} / \mathrm{K}$-ATPase-mediated cardioprotective signaling. Na/K-ATPase $\alpha 1$, the only known Srcinteracting $\alpha$-isoform (Tian et al., 2006; Xie et al., 2015a; Madan et al., 2017), is also the only isoform expressed in the pig kidney, which allowed us to explicitly test this hypothesis. The results presented in Fig. 1B indicated that ECG does 
A

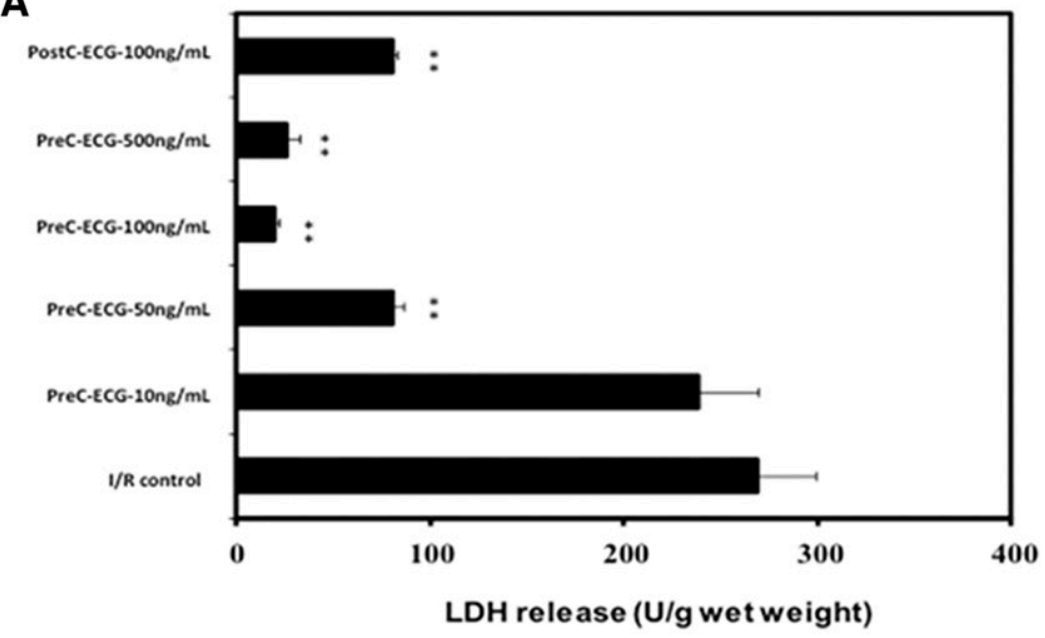

B

\section{I/R}
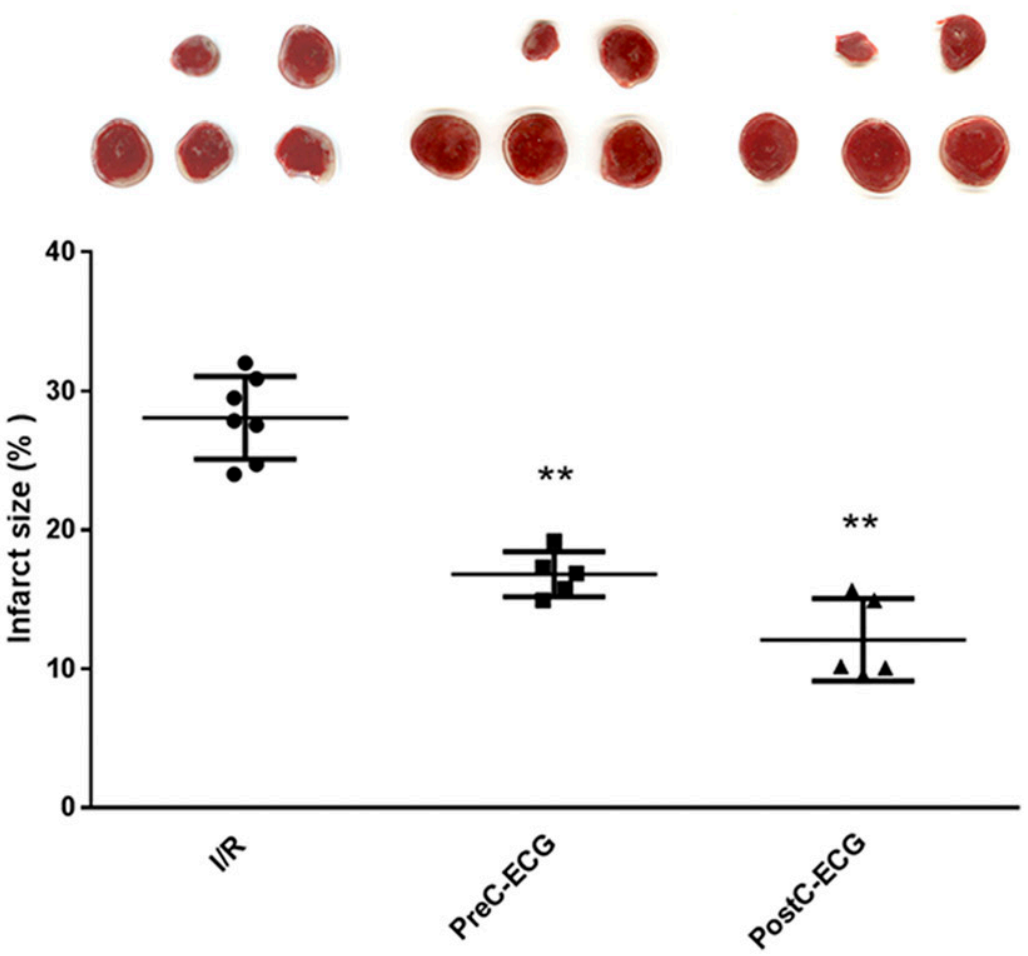

PostC-ECG
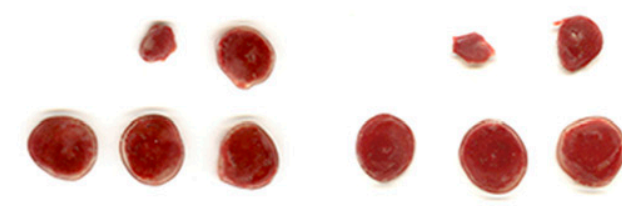

Fig. 7. Infarct-sparing effect of ECG PreC and PostC. (A) Coronary effluents were collected during the first 30 minutes of reperfusion and LDH was measured as described in Materials and Methods. Values are presented as mean \pm S.E.M. of four to seven rat hearts in each group. ${ }^{*} P P<0.01$ vs. I/R control. (B) Infarct size expressed as a percentage of the area at risk (equivalent to total ventricle), measured after 120 minutes of reperfusion as described in Materials and Methods. Data are presented as mean \pm S.E.M. of five to seven rat hearts in each group. $*_{*} P<0.01$ vs. I/R control. modulate the $\mathrm{Na} / \mathrm{K}$-ATPase/Src receptor in vitro. Based on the mechanism described for dietary concentration of another major green galloyl-type tea catechin (epigallocatechin-3-gallate) (Ochiai et al., 2009), it is tempting to speculate that ECG-induced modulation of Na/K-ATPase conformation occurs through major phospholipids present in the pig kidney preparation.

In the Langendorff-perfused rat heart, which abundantly (80\%) expresses the $\alpha 1$ isoform of $\mathrm{Na} / \mathrm{K}$-ATPase, dietary concentrations of ECG dose dependently activated intracellular kinases including ERK, Akt, and the cardioprotective $\mathrm{PKC} \varepsilon$ in a CTS-like manner (Fig. 3). Consistently, these concentrations of ECG, given transiently prior to (preconditioning) or after (postconditioning) 30-minute zero-flow ischemia also provided a degree of protection of cardiac structure and function comparable to those achieved with ischemic- or CTS-based preconditioning and PostC. Namely, we recorded a recovery of contractile function in excess of $70 \%$, a reduced amount of $\mathrm{LDH}$ release, and an infarct size under $20 \%$ of the area at risk (Figs. 4 and 7; Supplemental Fig. 1). Figure 5 shows a dose-dependent protective effect of ECG against I/R-induced alterations of the maximal Na/K-ATPase hydrolytic capacity of crude homogenates from hearts reperfused for 30 minutes after 30 minutes of ischemia. In the conditions of this assay, this likely reflects protection against I/R-induced alterations of the $\mathrm{Na} / \mathrm{K}$-ATPase $\alpha 1$ protein complex at the membrane that precedes cell death (Belliard et al., 2013), rather than a mere consequence of decreased substrate 
A

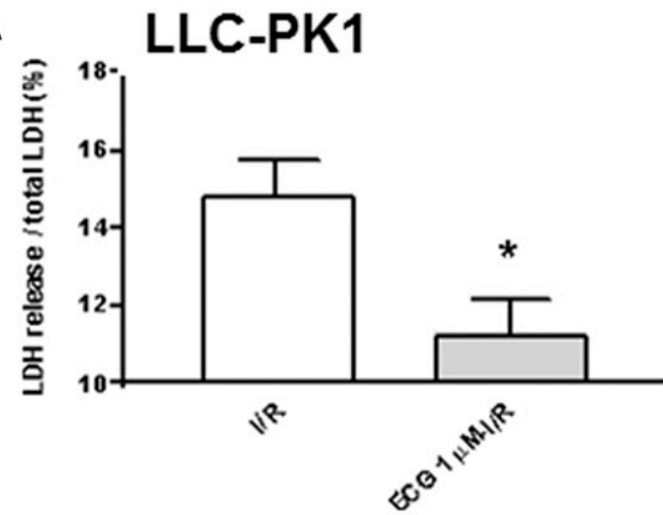

B

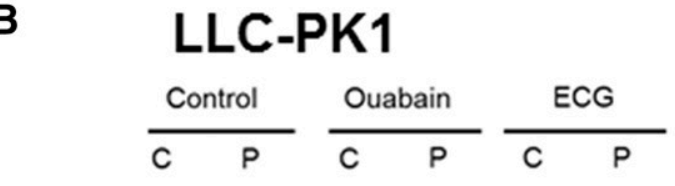

PKC $\varepsilon$

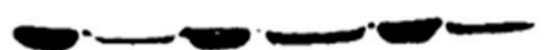

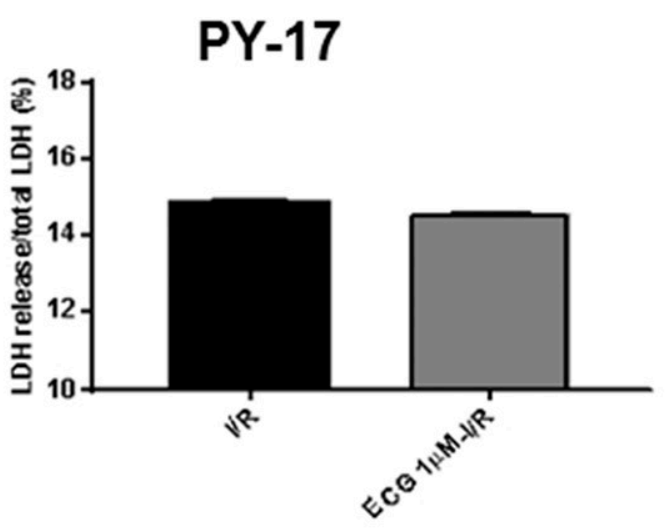
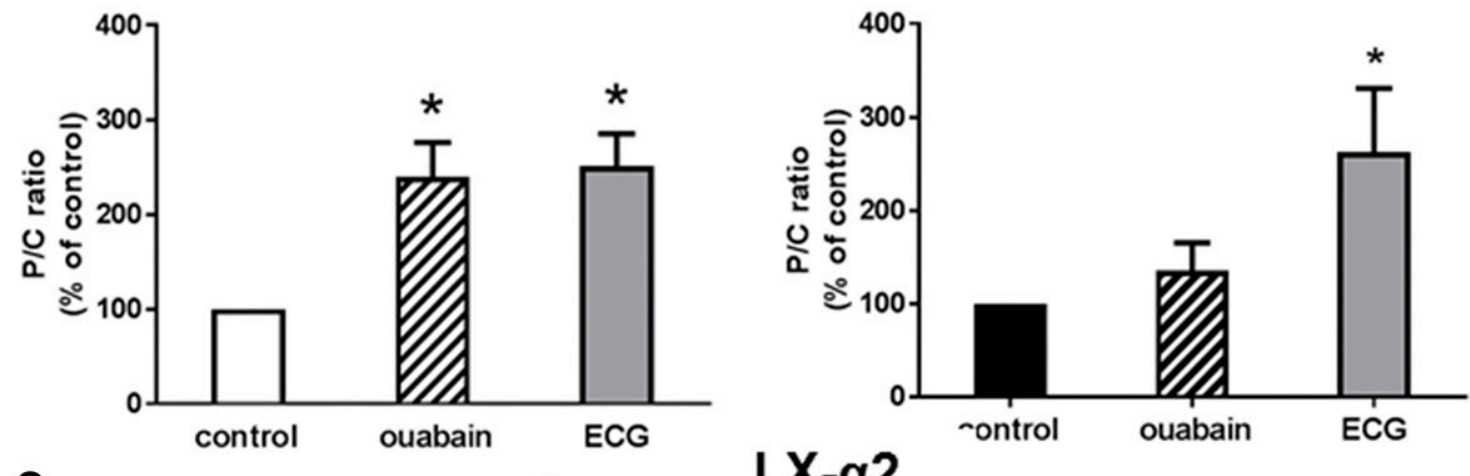

C

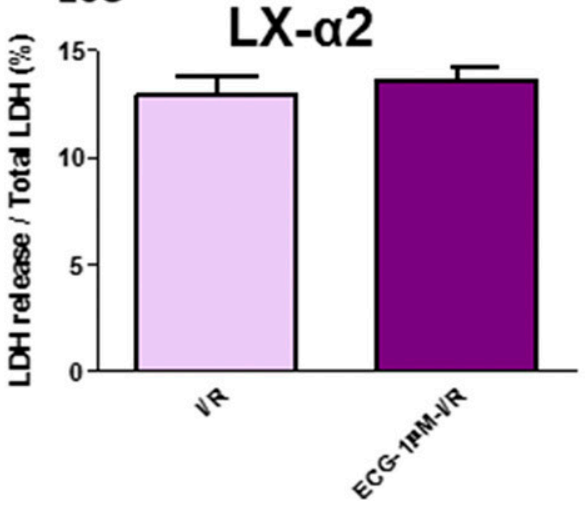

Fig. 8. Na/K-ATPase $\alpha 1$ in ECG-induced protection against simulated I/R in renal epithelial cells. Parental LLC-PK1 cells expressing $100 \%$ of their endogenous pig Na/K-ATPase $\alpha 1$ protein, a stable line with a $\sim 85 \% \mathrm{Na} / \mathrm{K}-\mathrm{ATPase} \alpha 1$ knockdown cell line established from LLC-PK-1 using small interfering RNA (PY-17), or a stable cell line, where the Na/K-ATPase $\alpha 2$ isoform was expressed to rescue PY-17, was used. Ouabain was used at $10 \mathrm{nM}$ for 15 minutes. ECG was used at $1 \mu \mathrm{g} / \mathrm{ml}$ for 15 minutes. (A) LDH released in the supernatant/total LDH ratios was measured as an index of post I/R cell survival. Values are mean \pm S.E.M. of five independent experiments for each condition. $* P<0.05$; vs. I/R control. (B) Upper panels: representative immunoblots. Lower panels: activation quantified as ratios of particulate-to-cytosolic ( $\mathrm{PKC} \varepsilon$ ), normalized to control (untreated). Values are mean \pm S.E.M. of three independent experiments for each condition. ${ }^{*} P<0.05$ vs. control (untreated). C, cytosolic; $\mathrm{P}$, particulate. (C) LDH released in the supernatant/total LDH ratios was measured as an index of post I/R cell survival. Values are mean \pm S.E.M. of six to 10 independent experiments for each condition.

availability as would be observed in situ before full reperfusion. It is also unlikely to be secondary to tissue damage (Inserte et al., 2005). This Na/K-ATPase sparing effect of ECG preconditioning was also dose dependent, and comparable to the protection achieved with ischemic preconditioning (Elmoselhi et al., 2003; Yorozuya et al., 2004; Inserte et al.,
2006) or CTS pre/postconditioning (Yorozuya et al., 2004; Belliard et al., 2013; Duan et al., 2018). The role of ERK and Akt activations observed in Fig. 3 in ECG-induced PreC remains to be explored, but pharmacological inhibition using a PKC $\varepsilon$ TIP and 5-HD revealed that $\mathrm{PKC} \varepsilon$ and mitochondrial $\mathrm{K}_{\mathrm{ATP}}$ channel opening are required for both PreC and PostC by ECG. 
Overall, the aforementioned properties add to a growing list of common features between ECG and CTS. Both have positive inotropic properties, which in the first approximation make them undesirable in the ischemic heart since they increase myocardial work and oxygen consumption. In this respect, it is important to note that the preconditioning protocols we used for both ouabain (Pierre et al., 2007) and ECG (Figs. 2 and 4) included a washout period prior to the index ischemia, which prevented such a possible impact. However, it is also worth mentioning that we developed a PostC ouabain protocol using a concentration that is well below the inotropic threshold (Duan et al., 2018), while the results presented in Fig. 6 suggest that the ECG PostC protocol is protective even at the inotropic concentration of $100 \mathrm{ng} / \mathrm{ml}$. This, and a number of mechanistic attributes, clearly set apart those two cardioprotective compounds. For instance, while $\mathrm{PKC} \varepsilon$ activation is a common characteristic of numerous forms of cardioprotection against I/R, most notoriously ischemic PreC and PostC (Cohen and Downey, 2015), the mechanism of PKC $\varepsilon$ activation induced by ECG and other tea catechins is quite unique and distinct from the one triggered by the CTS ouabain (Pasdois et al., 2007). Indeed, we have reported that $\mathrm{PKC} \varepsilon$ activation by tea catechins was independent from their pro-oxidant properties ( $\mathrm{Li}$ et al., 2008), in contrast to the reactive oxygen species-dependent effect of ouabain preconditioning (Pasdois et al., 2007). We have also previously shown that ECG increases myocardial contractility without increasing intracellular calcium ( $\mathrm{Li}$ et al., 2008), in contrast to the wellestablished $\mathrm{Na}^{+} / \mathrm{Ca}^{2+}$-dependent inotropic effect of CTS such as ouabain (Bai et al., 2013). Consistent with these earlier findings, mechanistic studies conducted in a mammalian system where $\mathrm{Na} / \mathrm{K}$-ATPase $\alpha 1$ was depleted using small interfering RNA showed that in contrast to ouabain ECG-induced activation of $\mathrm{PKC} \varepsilon$ does not require $\mathrm{Na}$ / K-ATPase expression (Fig. 8B). Critically, I/R studies in this cell system also revealed that $\mathrm{Na} / \mathrm{K}-\mathrm{ATPase}$ expression is required for ECG-induced protection (Fig. 8A). This prompted us to tease out the respective roles of $\mathrm{Na}$ / $\mathrm{K}$-ATPase ion-pumping versus $\mathrm{Na} / \mathrm{K}$-ATPase/Src receptor function in ECG-induced protection. To this end, we used a stable cell line derived from $\mathrm{PY}-17$, in which $\mathrm{Na} / \mathrm{K}$-ATPase $\alpha 1$ is replaced by the $\alpha 2$ isoform of $\mathrm{Na} / \mathrm{K}-\mathrm{ATPase}$ to rescue the ion-pumping activity but not the Src-modulatory function (Xie et al., 2015a). As shown in Fig. 8C, ECG did not protect LX- $\alpha 2$ cells, and it was therefore concluded that $\mathrm{Na} /$ $\mathrm{K}$-ATPase $\alpha 1 / \mathrm{Src}$ receptor function is required. Taken together, these studies reveal the key role of Na/K-ATPase/ Src receptor function in ECG-induced protection against I/R-induced cell death. In contrast to ouabain-induced protection, in which $\mathrm{PKC} \varepsilon$ activation is downstream from $\mathrm{Na}$ / K-ATPase/Src activation (Pierre et al., 2007), Na/K-ATPase/ Src is not required for ECG-induced $\mathrm{PKC} \varepsilon$ activation. Future studies may reveal whether ERK and Akt are required for ECG-mediated protection and clarify the respective roles of $\mathrm{Na} / \mathrm{K}$-ATPase/Src and $\mathrm{PKC} \varepsilon$ in their activation.

In our ex vivo protocol, the protective effect of $100 \mathrm{nM} \mathrm{ECG}$ provided as part of a standardized green tea extract YF170402-1 was comparable to those observed using $100 \mathrm{nM}$ ECG alone, which ruled out a major interaction between various tea components within the whole extract and is consistent with a main role of ECG in the protection conferred by the extract. Given the higher bioavailability (Choi et al., 2017), lower toxicity, and higher stability at the intracellular level of ECG compared with its more commonly studied counterpart epigallocatechin-3-gallate, we propose that ECG contribution to the cardioprotective effect of green tea consumption may be more substantial than initially thought. Consequently, green tea extracts with higher ECG content may be more likely to provide cardioprotection. Basic and clinical research continues to support the effectiveness and feasibility of conditioning interventions, but it is widely recognized that translation of experimental results into the clinical setting has been challenging in large part due to interference from confounding risk factors, comorbidities, and co-medications that alter some of the signaling pathways. In that context, further investigations including in vivo validation seem suitable to test the novel and unique ECG cardioprotective pathway uncovered by the present study since it is likely to be a key contributor to the reported cardiovascular benefits of green tea consumption.

\section{Authorship Contributions}

Participated in research design: Qi, Wan, Xie, D. Li, Pierre.

Conducted experiments: Qi, Yang, Jiang, Zhu, T. Li.

Contributed new reagents or analytic tools: Wang.

Performed data analysis: Qi, Yang, Jiang, Xu.

Wrote or contributed to the writing of the manuscript: Qi, Yang, Jiang, Xu, D. Li, Pierre.

\section{References}

Babich H, Schuck AG, Weisburg JH, and Zuckerbraun HL (2011) Research strategies in the study of the pro-oxidant nature of polyphenol nutraceuticals. J Toxicol 2011: 467305.

Baghdadi M, Endo H, Takano A, Ishikawa K, Kameda Y, Wada H, Miyagi Y, Yokose $\mathrm{T}$, Ito H, Nakayama H, et al. (2018) High co-expression of IL-34 and M-CSF correlates with tumor progression and poor survival in lung cancers. Sci Rep 8:418.

Bai Y, Morgan EE, Giovannucci DR, Pierre SV, Philipson KD, Askari A, and Liu L (2013) Different roles of the cardiac $\mathrm{Na}^{+} / \mathrm{Ca}^{2+}$-exchanger in ouabain-induced inotropy, cell signaling, and hypertrophy. Am J Physiol Heart Circ Physiol 304: H427-H435.

Belliard A, Sottejeau Y, Duan Q, Karabin JL, and Pierre SV (2013) Modulation of cardiac $\mathrm{Na}^{+}, \mathrm{K}^{+}$-ATPase cell surface abundance by simulated ischemiareperfusion and ouabain preconditioning. Am J Physiol Heart Circ Physiol 304:H94-H103.

Chen Z, Spahn DR, Zhang X, Liu Y, Chu H, and Liu Z (2016) Morphine postconditioning protects against reperfusion injury: the role of protein kinase C-epsilon, extracellular signal-regulated kinase 1/2 and mitochondrial permeability transition pores. Cell Physiol Biochem 39:1930-1940.

Choi EH, Lee DY, Kim S, Chung JO, Choi JK, Joo KM, Jeong HW, Kim JK, Kim WG, and Shim SM (2017) Influence of flavonol-rich excipient food (onion peel and Dendropanax morbifera) on the bioavailability of green tea epicatechins in vitro and in vivo. Food Funct 8:3664-3674.

Cohen MV and Downey JM (2015) Signalling pathways and mechanisms of protection in pre- and postconditioning: historical perspective and lessons for the future. Br J Pharmacol 172:1913-1932.

Darra E, Shoji K, Mariotto S, and Suzuki H (2007) Protective effect of epigallocatechin-3-gallate on ischemia/reperfusion-induced injuries in the heart: STAT1 silencing flavonoid. Genes Nutr 2:307-310.

Duan Q, Madan ND, Wu J, Kalisz J, Doshi KY, Haldar SM, Liu L, and Pierre SV (2015) Role of phosphoinositide 3-kinase IA (PI3K-IA) activation in cardioprotection induced by ouabain preconditioning. J Mol Cell Cardiol 80: $114-125$.

Duan Q, Xu Y, Marck PV, Kalisz J, Morgan EE, and Pierre SV (2018) Preconditioning and postconditioning by cardiac glycosides in the mouse heart. $J$ Cardiovasc Pharmacol 71:95-103.

D’Urso G, Frascarelli S, Zucchi R, Biver T, and Montali U (2008) Cardioprotection by ouabain and digoxin in perfused rat hearts. J Cardiovasc Pharmacol 52:333-337.

Elmoselhi AB, Lukas A, Ostadal P, and Dhalla NS (2003) Preconditioning attenuates ischemia-reperfusion-induced remodeling of $\mathrm{Na}^{+}-\mathrm{K}^{+}$-ATPase in hearts. $\mathrm{Am}$ $J$ Physiol Heart Circ Physiol 285:H1055-H1063.

Feng W, Cherednichenko G, Ward CW, Padilla IT, Cabrales E, Lopez JR, Eltit JM, Allen PD, and Pessah IN (2010) Green tea catechins are potent sensitizers of ryanodine receptor type 1 (RyR1). Biochem Pharmacol 80:512-521.

Fung ST, Ho CK, Choi SW, Chung WY, and Benzie IF (2013) Comparison of catechin profiles in human plasma and urine after single dosing and regular intake of green tea (Camellia sinensis). Br J Nutr 109:2199-2207.

Higdon JV and Frei B (2003) Tea catechins and polyphenols: health effects, metabolism, and antioxidant functions. Crit Rev Food Sci Nutr 43:89-143. 
Inagaki K, Churchill E, and Mochly-Rosen D (2006) Epsilon protein kinase C as a potential therapeutic target for the ischemic heart. Cardiovasc Res 70:222-230. Inserte J, Garcia-Dorado D, Hernando V, Barba I, and Soler-Soler J (2006) Ischemic preconditioning prevents calpain-mediated impairment of $\mathrm{Na}^{+} / \mathrm{K}^{+}$-ATPase activity during early reperfusion. Cardiovasc Res 70:364-373.

Inserte J, Garcia-Dorado D, Hernando V, and Soler-Soler J (2005) Calpain-mediated impairment of $\mathrm{Na}^{+} / \mathrm{K}^{+}$-ATPase activity during early reperfusion contributes to cell death after myocardial ischemia. Circ Res 97:465-473.

Jørgensen PL and Collins JH (1986) Tryptic and chymotryptic cleavage sites in sequence of $\alpha$-subunit of $\left(\mathrm{Na}^{+}+\mathrm{K}^{+}\right)$-ATPase from outer medulla of mammalian kidney. Biochim Biophys Acta 860 (3):570-576.

Kim HS, Quon MJ, and Kim JA (2014) New insights into the mechanisms of polyphenols beyond antioxidant properties; lessons from the green tea polyphenol, epigallocatechin 3-gallate. Redox Biol 2:187-195.

Kuriyama S, Shimazu T, Ohmori K, Kikuchi N, Nakaya N, Nishino Y, Tsubono Y, and Tsuji I (2006) Green tea consumption and mortality due to cardiovascular disease, cancer, and all causes in Japan: the Ohsaki study. JAMA 296:1255-1265.

Li D, Yang C, Chen Y, Tian J, Liu L, Dai Q, Wan X, and Xie Z (2008) Identification of a $\mathrm{PKC} \varepsilon$-dependent regulation of myocardial contraction by epicatechin-3-gallate. Am J Physiol Heart Circ Physiol 294:H345-H353.

Liang M, Cai T, Tian J, Qu W, and Xie ZJ (2006) Functional characterization of Srcinteracting Na/K-ATPase using RNA interference assay. J Biol Chem 281:19709-19719.

Madan N, Xu Y, Duan Q, Banerjee M, Larre I, Pierre SV, and Xie Z (2017) Srcindependent ERK signaling through the rat $\alpha 3$ isoform of $\mathrm{Na} / \mathrm{K}$-ATPase. $A m$ J Physiol Cell Physiol 312:C222-C232.

Marck PV and Pierre SV (2018) Na/K-ATPase signaling and cardiac pre/postconditioning with cardiotonic steroids. Int J Mol Sci 19:23-36.

Ochiai H, Takeda K, Soeda S, Tahara Y, Takenaka H, Abe K, Hayashi Y, Noguchi S, Inoue M, Schwarz S, et al. (2009) Epigallocatechin-3-gallate is an inhibitor of $\mathrm{Na}^{+}$, $\mathrm{K}^{+}$-ATPase by favoring the $\mathrm{E}_{1}$ conformation. Biochem Pharmacol 78:1069-1074

Pasdois P, Quinlan CL, Rissa A, Tariosse L, Vinassa B, Costa AD, Pierre SV, Dos Santos $\mathrm{P}$, and Garlid $\mathrm{KD}$ (2007) Ouabain protects rat hearts against ischemia-reperfusion injury via pathway involving src kinase, mitoK $_{\mathrm{ATP}}$, and ROS. Am J Physiol Heart Circ Physiol 292:H1470-H1478.

Pierre SV, Belliard A, and Sottejeau Y (2011) Modulation of $\mathrm{Na}^{+}-\mathrm{K}^{+}$-ATPase cell surface abundance through structural determinants on the $\alpha 1$-subunit. Am J Physiol Cell Physiol 300:C42-C48.
Pierre SV, Yang C, Yuan Z, Seminerio J, Mouas C, Garlid KD, Dos-Santos P, and Xie $\mathrm{Z}$ (2007) Ouabain triggers preconditioning through activation of the $\mathrm{Na}^{+}, \mathrm{K}^{+}$. ATPase signaling cascade in rat hearts. Cardiovasc Res 73:488-496.

Pittts and Tombs (2004) Coverslip hypoxia: a novel method for studying cardiac myocyte hypoxia and ischemia in vitro. Am J Physiol Heart Circ Physiol 287 (4): 1801-1812.

Tian J, Cai T, Yuan Z, Wang H, Liu L, Haas M, Maksimova E, Huang XY, and Xie ZJ (2006) Binding of Src to $\mathrm{Na}^{+} / \mathrm{K}^{+}$-ATPase forms a functional signaling complex. Mol Biol Cell 17:317-326

Xie J, Ye Q, Cui X, Madan N, Yi Q, Pierre SV, and Xie Z (2015a) Expression of rat Na-K-ATPase $\alpha 2$ enables ion pumping but not ouabain-induced signaling in $\alpha 1$ deficient porcine renal epithelial cells. Am J Physiol Cell Physiol $\mathbf{3 0 9}$ C373-C382.

Xie Z, Su W, Liu S, Zhao G, Esser K, Schroder EA, Lefta M, Stauss HM, Guo Z, and Gong MC (2015b) Smooth-muscle BMAL1 participates in blood pressure circadian rhythm regulation. $J$ Clin Invest 125:324-336.

Yang CS, Zhang J, Zhang L, Huang J, and Wang Y (2016) Mechanisms of body weight reduction and metabolic syndrome alleviation by tea. Mol Nutr Food Res 60: 160-174.

Ye Q, Li Z, Tian J, Xie JX, Liu L, and Xie Z (2011) Identification of a potential receptor that couples ion transport to protein kinase activity. J Biol Chem 286 $6225-6232$

Yorozuya T, Adachi N, Dote K, Nakanishi K, Takasaki Y, and Arai T (2004) Enhancement of $\mathrm{Na}^{+}, \mathrm{K}^{+}$-ATPase and $\mathrm{Ca}^{2+}$-ATPase activities in multi-cycle ischemic preconditioning in rabbit hearts. Eur $J$ Cardiothorac Surg 26:981-987.

Zhao Q, Shao L, Hu X, Wu G, Du J, Xia J, and Qiu H (2013) Lipoxin A 4 preconditioning and postconditioning protect myocardial ischemia/reperfusion injury in rats. Mediators Inflamm 2013:231351.

Address correspondence to: Dr. Sandrine V. Pierre, Marshall Institute for Interdisciplinary Research, Marshall University, Huntington, WV 25701. E-mail: pierres@marshall.edu; or Dr. Daxiang Li, State Key Laboratory of Tea Plant Biology and Utilization, Anhui Agricultural University, Hefei 230036, Anhui, China. E-mail: dxli@ahau.edu.cn 